Efektor, Volume 7 Issue 2, 2020, Pages 98 - 108

Available online at: http://ojs.unpkediri.ac.id/index.php/efektor-e

https://doi.org/10.29407/e.v7i2.14473

\title{
Bauran Pemasaran Jasa, Citra, dan Kepuasan Mahasiswa: Sebuah Kajian Perguruan Tinggi Swasta di Kediri
}

\author{
Sri Aliami ${ }^{1}$, Ema Nurzainul Hakimah² \\ srialiami@unpkediri.ac.id1, emahakimah@unpkediri.ac.id² \\ Universitas Nusantara PGRI Kediri 1,2
}

\begin{abstract}
Business in education can be classified as a service business. The main principle to run this type of business is to develop and maintain the trust of society as well as to give satisfaction value through various strategies. Based on the fact universities must be able to manage the available resources to fulfill the students' expectations. The objective of this study is to analyze the effect of the service marketing mix and image of higher education on partial and simultaneous satisfaction. Service marketing mix in this research cover product, price, place, promotion, people, physical evidence, and process. At the same time, the indicators of an image are reputation, tradition, and the identity of a university. Students' satisfaction can be identified by their desire to reuse the product, the level of file a complaint, giving recommendations to other consumers, the pride of using the product, and obey the regulations. The population is the students of the University of Nusantara PGRI Kediri. The sample total of 81 students using the technique proportional stratified sampling. Used a questionnaire to collect the data and analyzed using multiple linear regression. The Results of the research proved that service marketing mix and image influence significantly in both partial and stimulant towards the satisfaction.
\end{abstract}

Keywords: satisfaction, service marketing mix, image

\begin{abstract}
Abstrak
Bisnis pendidikan merupakan bisnis jasa. Membangun dan menjaga kepercayaan serta memberikan nilai kepuasan merupakan prinsip utama berbisnis. Berdasarkan fakta, perguruan tinggi harus dapat mengelola sumber daya untuk memenuhi harapan mahasiswa. Adapun kajian dalam penelitian ini untuk mengetahui pengaruh bauran pemasaran jasa dan citra terhadap kepuasan secara parsial maupun simultan. Bauran pemasaran jasa digambarkan oleh produk, harga, saluran distribusi, promosi, orang yang terlibat dengan perusahaan, lingkungan fisik, dan proses. Citra terdiri atas reputasi, tradisi, dan identitas perguruan tinggi. Kepuasan mahasiswa ditandai dengan adanya hasrat pembelian ulang, rendahnya hasrat mengajukan keluhan, merekomendasi ke orang lain, adanya rasa bangga, dan berusaha tetap mematuhi peraturan. Populasi dalam penelitian adalah mahasiswa Universitas Nusantara PGRI Kediri. Sampel penelitian sejumlah 81 mahasiswa dengan teknik proportional stratified sampling. Data dikumpulkan melalui angket dengan teknik analisis regresi linier berganda. Hasil penelitian ini membuktikan apabila bauran pemasaran jasa dan citra berpengaruh signifikan secara terpisah maupun bersama-sama terhadap kepuasan.
\end{abstract}

Kata kunci: kepuasan, bauran pemasaran jasa, citra

\section{PENDAHULUAN}

Semakin banyak berdiri perguruan tinggi swasta (PTS) dan program konsentrasi baru, maka semakin ketat persaingan antarperguruan tinggi. Perguruan tinggi akan menghadapi tiga bidang persaingan yaitu dalam manajemen, dinamika pembelajaran, dan 


\section{Efektor, Volume 7 Issue 2, 2020, Pages 98 - 108 \\ Sri Aliami, Ema Nurzainul Hakimah}

pembentukan nilai karakter. Aspek lain yang harus mendapatkan perhatian yakni tentang struktur institusi dan budaya berpikir yang berhubungan dengan status akreditasi, hak intelektual, dan institusi sebagai suatu komunitas. Berdasarkan data dari Direktorat Jendral Pendidikan Tinggi Tahun 2017, PTS di Jawa Timur sebagaimana dalam tabel di bawah ini.

Tabel 1: Perguruan Tinggi Swasta Jawa Timur

\begin{tabular}{cllc}
\hline No. & & Bentuk Instansi & Jumlah \\
\hline 1 & Universitas & & 88 \\
2 & Institut & & 13 \\
3 & Sekolah Tinggi & & 130 \\
4 & Akademi & & 49 \\
5 & Politeknik & 9 \\
& & Jumlah & 289 \\
\hline
\end{tabular}

Sumber : Kopertis Wilayah VII Jawa Timur, Tahun 2017

Perguruan tinggi sebagai perusahaan bisnis jasa memiliki prinsip utama yakni menguatkan dan mempertahankan kepercayaan masyarakat serta pada akhirnya merasakan puas dengan keberadaan internal dan eksternal lembaga. Oleh karena itu, perguruan tinggi perlu mengetahui strategi bauran pemasaran yang diterapkan dan citra perusahaan berdasarkan pandangan masyarakat. Selain itu, perguruan tinggi harus mampu mengevaluasi tingkat kepuasan mahasiswa.

Ham dan Hayduk dalam Alma (2016:98), terdapat beberapa faktor yang mempengaruhi organisasi dalam semua kategori, baik yang berorientasi pada laba maupun sosial, dan dalam ruang lingkup nasional maupun internasional, termasuk lembaga pendidikan atau perguruan tinggi. Ketiga faktor tersebut meliputi kualitas layanan, kepuasan konsumen, dan hasrat perilaku. Pemehuhan harapan konsumen dapat berdampak pada tanggapan atau respon yang dirasakan oleh mahasiswa untuk menyetujui atau menolak. Selain itu, agar terbentuk citra yang baik terhadap sejumlah calon mahasiswa, bukan hanya pemenuhan keinginan dan kebutuhan saja tapi harus lebih ditingkatkan komponen bauran pemasarannya. Zeithaml and Bitner (2000:23), bahwa elemen marketing mix terdiri atas: product, price, place, promotion, people, physical evidence, dan process.

Dengan strategi paduan pemasaran yang tepat di perguruan tinggi ditargetkan bisa memberikan rasa puas kepada mahasiswa. Ketersediaan variasi pilihan produk yang lengkap, status akreditasi, biaya pendidikan, promosi yang tepat sasaran, tempat strategis, tenaga pendidik dan kependidikan yang profesional, kondisi kampus aman, dan sistem manajemen yang baik tentu akan menciptakan kepuasan terhadap mahasiswa. Hasil penelitian menunjukkan bahwa bauran pemasaran berpengaruh pada kepuasan siswa (Soedijati:2011). Penelitian lain juga membuktikan apabila bauran pemasaran memiliki pengaruh terhadap kepuasan (Cengiz dan Yayla:2007). Selanjutnya hal ini dapat dianalogikan apabila dapat memenuhi kebutuhan dan keinginan mahasiswa berimplikasi pada terbentuknya citra program studi atau perguruan tinggi. Putro (2016), membuktikan apabila citra perguruan tinggi berpengaruh signifikan terhadap kepuasan mahasiswa. Demikian juga, Bloemer et al (2002), membuktikan citra produk berpengaruh terhadap kepuasan. Mahasiswa memperoleh 


\section{Efektor, Volume 7 Issue 2, 2020, Pages 98 - 108}

Sri Aliami, Ema Nurzainul Hakimah

kepuasan dalam pelaksanaan program bauran pemasaran jasa dan pembentukan citra merupakan modal dasar bagi perguruan tinggi.

Dalam kenyataan, beberapa PTS banyak mendapatkan pengaduan dari para mahasiswa. Mulai dari masalah transparansi biaya pendidikan, biaya terlalu mahal, sarana prasarana atau fasilitas belajar mengajar dan fasilitas umum (ketersediaan dan kelayakan pakai) , transparansi nilai, kedisiplinan dosen, dosen killer, proses layanan akademik yang kurang efektif, pelayanan tenaga administrasi kurang ramah dan lambat, ketersediaan parkir kurang, suasana kampus kurang menyenangkan dan sampai dengan masalah ketersediaan literatur di perpustakaan kurang up to date (http://ft.unmul.ac.id/ index.php/id/keluhanpelanggan/keluhan. 11 Juli 2013 11:24:32 GMT). Sebagai dampaknya, mahasiswa malas mengikuti proses pembelajaran, sering absen atau tidak aktif mengikuti perkuliahan, dan pada akhirnya mempengaruhi nilai akhir yang dicapai oleh mahasiswa rendah. Universitas Nusantara PGRI Kediri sebagai perguruan tinggi swasta di Kota Kediri, dimungkinkan merasakan realita permasalahan tersebut.

Berdasarkan paparan di atas, Universitas Nusantara PGRI Kediri perlu mengkaji pengaruh faktor bauran pemasaran jasa dan citra perguruan tinggi terhadap kepuasan mahasiswa. Oleh karena itu, masalah utama dalam penelitian ini yaitu tentang pengaruh bauran pemasaran jasa dan citra terhadap kepuasan.

\section{METODOLOGI PENELITIAN}

Pendekatan dalam penelitian ini menggunakan pendekatan kuantitatif. Sesuai dengan judul yang dipilih, terdapat dua varibel yakni kepuasan mahasiswa $(Y)$ dan variabel bauran pemasaran jasa (X1) dan citra (X2).

Definisi konseptual penelitian: (1) Bauran pemasaran jasa merupakan unsur-unsur yang dikendalikan oleh suatu organisasi dan dapat digunakan untuk memuaskan atau berkomunikasi dengan pelanggan (Zeithaml dan Bitner, 2000: 18). (2) Citra adalah kesan keseluruhan yang diciptakan di benak konsumen tentang perusahaan (Nguyen dan Leblanc, 2001: 303). (3) Kepuasan pelanggan yaitu: tingkatan yang dirasakan terhadap produk sesuai dengan harapan pembeli ( Kotler dan Amstrong, 2015: 13). Sedangkan, definisi operasional penelitian: (1) Bauran pemasaran jasa merupakan kegiatan pemasaran untuk pemenuhan kebutuhan dan keinginan mahasiswa. Indikator variabel ini terdiri atas: product, price, place, promotion, people, physical evidence dan process. (2) Citra merupakan kesan dan keyakinan yang ditimbulkan dari keseluruhan yang ditawarkan Universitas Nusantara PGRI Kediri. Indikator variabel citra terdiri atas: reputasi, tradisi, dan identitas perguruan tinggi. (3) Kepuasan mahasiswa: suatu persepsi evaluasi selama menjadi mahasiswa. Indikator kepuasan mahasiswa meliputi: adanya hasrat pembelian ulang, kecilnya hasrat untuk mengajukan keluhan, merekomendasi, adanya rasa bangga, rasa ingin tetap mematuhi peraturan, dan adanya kepercayaan.

Penelitian dilaksanakan di Kampus 1, Jalan K. H. Achmad Dahlan 76 Kediri. Waktu dalam penelitian terhitung mulai 24 Oktober 2018 sampai 26 Oktober 2019. Populasi penelitian yakni seluruh mahasiswa Universitas Nusantara PGRI Kediri yang telah 
membayar lunas pada saat pengambilan data merupakan populasi dalam penelitian ini. . Berdasarkan data dari Biro Administrasi Akademik dari hasil sinkronisasi dengan Biro AdministrasiUmum, jumlah mahasiswa Universitas Nusantara PGRI Kediri sebanyak 4.916 mahasiswa. Secara lengkap populasi mahasiswa disajikan sebagai berikut:

Tabel 2. Populasi

\begin{tabular}{rlrrrr}
\hline No. & \multicolumn{1}{c}{ Program Studi } & $\mathbf{2 0 1 6}$ & $\mathbf{2 0 1 7}$ & $\mathbf{2 0 1 8}$ & $\mathbf{2 0 1 9}$ \\
\hline 1. & Bimbingan Konseling & 35 & 32 & 44 & 52 \\
2. & Pendidikan Sejarah & 10 & 15 & 23 & 12 \\
3. & PPKn & 8 & 10 & 12 & 10 \\
4. & Pendidikan Ekonomi & 15 & 14 & 22 & 9 \\
5. & Pendidikan Matematika & 24 & 33 & 36 & 31 \\
6. & Pendidikan Biologi & 14 & 15 & 14 & 21 \\
7. & Pendidikan Bhs. Indonesia & 23 & 26 & 41 & 31 \\
8. & Pendidikan Bhs. Inggris & 23 & 42 & 42 & 61 \\
9. & Penjaskesrek & 180 & 186 & 207 & 196 \\
10. & PGSD & 70 & 112 & 159 & 186 \\
11. & PG-PAUD & 16 & 24 & 29 & 30 \\
12. & Manajemen & 120 & 183 & 303 & 288 \\
13. & Akuntansi & 39 & 59 & 107 & 110 \\
14. & Sistem Informasi & 33 & 33 & 65 & 50 \\
15. & Teknik Mesin & 52 & 60 & 112 & 100 \\
16. & Teknik Industri & 12 & 13 & 4 & 12 \\
17. & Teknik Informatika & 115 & 129 & 223 & 258 \\
18. & Peternakan & 10 & 3 & 18 & 21 \\
19. & Keperawatan & 11 & 18 & 18 & 21 \\
& & & 1.016 & 1.491 & 1499 \\
& & & 4.916 & & \\
\hline
\end{tabular}

Sumber: Biro Administrasi Akademik 2019 (diolah)

Berdasarkan populasi di atas, dalam penelitian ini ditentukan target populasi dengan kreteria sebagai berikut: (1) Mahasiswa yang sudah mendaftar ulang dan aktif mengikuti perkuliahan, secara otomatis telah mengeluarkan sejumlah uang untuk biaya sumbangan pembinaan pendidikan (SPP) maupun biaya lain selama mengikuti pendidikan. (2) Mahasiswa yang telah mengikuti perkuliahan dengan minimal 110 SKS yang telah ditempuh, diasumsikan telah merasakan berbagai sarana dan prasarana serta berbagai bentuk layanan, baik dari struktural, dosen, maupun tenaga kependidikan. Dengan demikian, mahasiswa yang memenuhi pada kreteria ini yaitu mahasiswa angkatan tahun akademik 2016, sejumlah 810 mahasiswa dan selanjutnya digunakan sebagai dasar untuk penentuan sampel penelitian.

Sampel dalam penelitian dianggap dan diharapkan mampu mewakili target populasi. Penentuan jumlah sampel berdasarkan pendapat Arikunto (2014: 112), apabila sampel lebih dari 100 orang dapat diambil 10-15\%. Penelitian ini mengambil $10 \%$ dari jumlah target populasi atau sejumlah 81 mahasiswa. Teknik penentuan sampel penelitian menggunakan teknik proportional stratified sampling.

Sedangkan untuk alokasi distribusi sampel pada setiap program studi mengacu pada pendapat (Riduwan 2017):

$$
n i=\frac{N i}{N}---\times n
$$


Efektor, Volume 7 Issue 2, 2020, Pages 98 - 108

Sri Aliami, Ema Nurzainul Hakimah

Keterangan :

$\mathrm{ni}=$ sampel menurut program studi

$\mathrm{n}$ = sampel seluruhnya

$\mathrm{Ni}=$ populasi menurut program studi

$\mathrm{N}=$ populasi seluruhnya.

Tabel 3. Subjek Penelitian Berdasarkan Target Populasi

\begin{tabular}{rlrr}
\hline No. & \multicolumn{1}{c}{ Prodi. } & Target Populasi & Subjek \\
\hline 1. & Bimbingan Konseling & 35 & 4 \\
2. & Pendidikan Sejarah & 10 & 1 \\
3. & PPKn & 8 & 1 \\
4. & PE-Akuntansi & 15 & 2 \\
5. & Pendidikan Matematika & 24 & 2 \\
6. & Pendidikan Biologi & 14 & 1 \\
7. & Pendidikan Bhs. Indonesia & 23 & 2 \\
8. & Pendidikan Bhs. Inggris & 23 & 2 \\
9. & Penjaskesrek & 180 & 18 \\
10. & PGSD & 70 & 7 \\
11. & PG-PAUD & 16 & 2 \\
12. & Manajemen & 120 & 12 \\
13. & Akuntansi & 39 & 4 \\
14. & Sistem Informasi & 33 & 3 \\
15. & Teknik Mesin & 52 & 5 \\
16. & Teknik Industri & 12 & 1 \\
17. & Teknik Informatika & 115 & 12 \\
18. & Peternakan & 10 & 1 \\
19. & Keperawatan & 11 & 1 \\
& Total & 810 & 81 \\
\hline
\end{tabular}

Sumber: Biro Administrasi Akademik 2019 (diolah)

Instrumen disusun melalui beberapa tahapan: (1) identifikasi variabel, (2) variabel dijabarkan ke dalam dimensi faktor/indikator, (3) setiap indikator dijabarkan ke dalam item (butir pertanyaan), dan (4) item instrumen dilengkapi dan disempurnakan dengan kalimat yang jelas.

Tabel 4. Variabel Penelitian, Dimensi, dan Butir Pernyataan sebagai Instrumen

\begin{tabular}{llll}
\hline \multicolumn{1}{c}{ Variabel } & Dimensi/Indikator & & \multicolumn{1}{c}{ Butir Pernyataan } \\
\hline $\begin{array}{l}\text { Bauran } \\
\text { Pemasaran }\end{array}$ & Product & - & Pilihan program studi bervariasi \\
& & - & Variasi UKM memberikan nilai manfaat \\
& Price & Biaya perkuliahan terjangkau \\
& & Pembayaran berbagai kegiatan akademik sesuai dengan nilai \\
& & manfaat \\
& Place & Dekat dengan fasilitas umum \\
& & Jangkauan transportasi umum \\
& Promotion & Iklan yang disampaikan oleh perguruan tinggi (PT) persuatif \\
& & PT memberikan kesempatan pada mahasiswa untuk \\
& & memperkenalkan kampus pada teman sejawat \\
& People & Manajemen PT memiliki kemampuan manajerial dalam \\
& & pengembangan PT
\end{tabular}


Efektor, Volume 7 Issue 2, 2020, Pages 98 - 108

Sri Aliami, Ema Nurzainul Hakimah

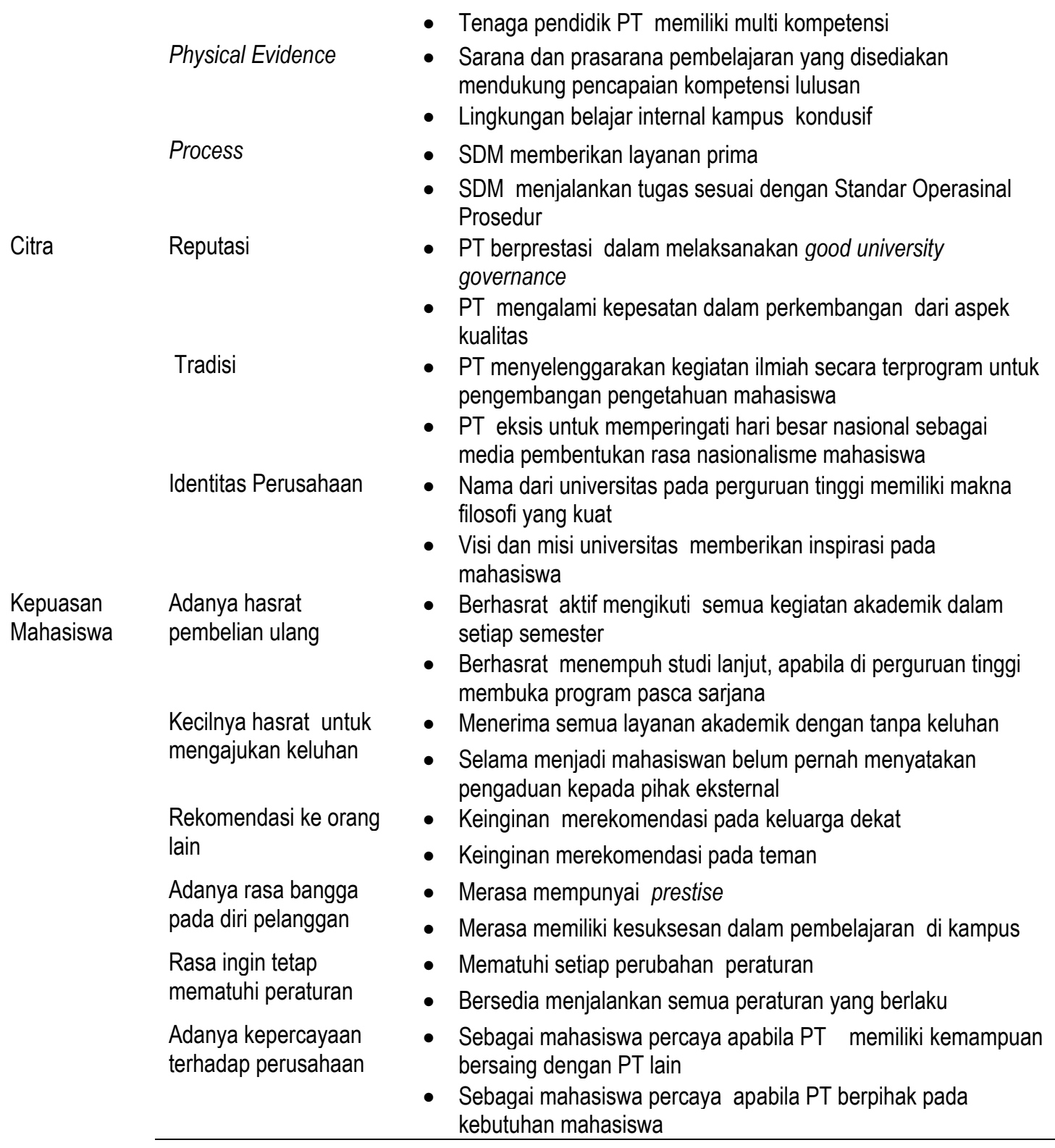

Pemberian skor menggunakan skala Likert, dalam bentuk pertanyaan tertutup. Instrumen penelitian sebelum didistribusikan pada responden terlebih dahulu diuji agar menghasilkan data yang valid dan reliabel. Dalam penelitian ini telah memenuhi kedua uji instrumen tersebut.

Teknik analisis dengan regresi linier berganda diawali dengan uji asumsi klasik. Dalam analisis data penelitian ini telah memenuhi asumsi-asumsi tersebut. Teknik ini untuk melihat pengaruh bauran pemasaran jasa $\left(X_{1}\right)$ dan citra $\left(X_{2}\right)$ terhadap kepuasan mahasiswa (Y) dengan menggunakan program SPSS versi 19 for Windows, dengan persamaan:

$$
Y=a+b_{1} X_{1}+b_{2} X_{2}+e
$$

Pengujian terhadap hipotesis dilakukan dengan cara:

1) Uji Signifikan Parameter Individual (Uji Statistik t).

2) Uji Regresi Simultan (Uji F) 
Efektor, Volume 7 Issue 2, 2020, Pages 98 - 108

Sri Aliami, Ema Nurzainul Hakimah

\section{HASIL DAN PEMBAHASAN}

Berdasarkan analisis data menggunakan regresi linier berganda, diringkas sebagai berikut.

Tabel 5. Hasil Analisis Regresi

Coefficients $^{\mathrm{a}}$

\begin{tabular}{|c|c|c|c|c|c|c|c|}
\hline \multirow[b]{2}{*}{ Model } & \multicolumn{2}{|c|}{$\begin{array}{c}\text { Unstandardized } \\
\text { Coefficients }\end{array}$} & \multirow{2}{*}{$\begin{array}{c}\begin{array}{c}\text { Standardized } \\
\text { Coefficients }\end{array} \\
\text { Beta }\end{array}$} & \multirow[b]{2}{*}{$t$} & \multirow[b]{2}{*}{ Sig. } & \multicolumn{2}{|c|}{ Collinearity Statistics } \\
\hline & $B$ & Std. Error & & & & Tolerance & VIF \\
\hline $1 \quad$ (Constant) &, 566 & ,290 & & 1,949 & ,055 & & \\
\hline $\mathrm{X} 1$ &, 536 & ,074 & ,530 & 7,257 &, 000 & 877 & 1,140 \\
\hline $\mathrm{X} 2$ & ,274 &, 046 & ,437 & 5,982 &, 000 & ,877 & 1,140 \\
\hline
\end{tabular}

Sumber: Lampiran SPSS

Dependent Variabel: kepuasan mahasiswa

$Y=a+b_{1} X_{1}+b_{2} X_{2}$

$=0,556+0,536 X_{1}+0,274 X_{2}$

Koefisien regresi dari semua variabel bebas menunjukkan angka positif. Hal ini berarti semua variabel bebas mempunyai hubungan positif terhadap variabel terikatnya. Dari kedua variabel bebas di atas yang paling dominan berpengaruh adalah bauran pemasaran jasa dengan koefisien regresi sebesar 0,536 . Persamaan regresi tersebut juga berarti :

$a=0,566$; bauran pemasaran jasa $\left(X_{1}\right)$, dan citra $\left(X_{2}\right)$ diasumsikan tidak memiliki pengaruh sama sekali $(=0)$ maka kepuasan mahasiswa adalah sebesar 0,566 satuan.

$b_{1}=0,536$; bauran pemasaran jasa $\left(X_{1}\right)$ naik 1 satuan dan citra $\left(X_{2}\right)$ tetap maka kepuasan mahasiswa akan meningkat sebesar 0,536 satuan.

$b_{2}=0,274$; citra $\left(X_{2}\right)$ naik 1 satuan dan bauran pemasaran jasa $\left(X_{1}\right)$ tetap maka kepuasan mahasiswa akan meningkat sebesar 0,274 satuan.

Uji Hipotesis untuk Regresi Simultan (uji F), dalam penelitian ini sebagai berikut:

Tabel 6. ANOVA ${ }^{a}$

\begin{tabular}{|lrrrrr}
\hline Model & Sum of Squares & df & Mean Square & F & Sig. \\
\hline Regression & 7,053 & 2 & 3,526 & 67,786 &, $000^{\mathrm{b}}$ \\
Residual & 4,058 & 78 &, 052 & & \\
Total & 11,111 & 80 & & & \\
\hline
\end{tabular}

Sumber : Data primer diolah, 2019

Dependent Variable: $Y$

Predictors: (Constant), X2, X1

Hasil pengujian menunjukkan nilai $F$ hitung sebesar 67,786 dengan signifikansi 0,000 . Dengan menggunakan batas signifikansi 0,05 , nilai signifikansi tersebut lebih kecil dari 0,05 . Dengan demikian, variabel bauran pemasaran jasa dan citra secara bersama-sama memiliki pengaruh signifikan terhadap kepuasan mahasiswa. Sedangkan untuk uji Signifikan Parameter Individual (Uji t), disajikan pada tabel 7 di bawah ini. 
Efektor, Volume 7 Issue 2, 2020, Pages 98 - 108

Sri Aliami, Ema Nurzainul Hakimah

Tabel 7. Hasil Uji signifikan Parameter Individual

\begin{tabular}{|c|c|c|c|c|c|c|c|c|}
\hline & \multirow[b]{3}{*}{ Model } & \multicolumn{5}{|c|}{ Coefficients $^{\mathrm{a}}$} & & \\
\hline & & \multicolumn{2}{|c|}{$\begin{array}{c}\text { Unstandardized } \\
\text { Coefficients }\end{array}$} & \multirow{2}{*}{$\begin{array}{c}\text { Standardized } \\
\text { Coefficients } \\
\text { Beta }\end{array}$} & \multirow[b]{2}{*}{$t$} & \multirow[b]{2}{*}{ Sig. } & \multicolumn{2}{|c|}{ Collinearity Statistics } \\
\hline & & $\mathrm{B}$ & Std. Error & & & & Tolerance & VIF \\
\hline \multirow[t]{3}{*}{1} & (Constant) & ,566 & ,290 & & 1,949 & ,055 & & \\
\hline & $\mathrm{X} 1$ & ,536 & ,074 & ,530 & 7,257 &, 000 & ,877 & 1,140 \\
\hline & $\mathrm{X} 2$ & ,274 & ,046 & ,437 & 5,982 &, 000 & ,877 & 1,140 \\
\hline
\end{tabular}

Sumber: Data primer diolah,2019

Dependent Variabel: kepuasan mahasiswa

Hasil pengujian pada tabel 7 menunjukkan, nilai t hitung untuk variabel X1 terhadap $Y$ pada nilai $t$ hitung $=7,257$ dengan signifikansi 0,000 . Dengan menggunakan batas signifikansi 0,05 , nilai signifikansi tersebut lebih kecil dari 0,05 dengan arah koefisien positif, sehingga hipotesis yang menyatakan bahwa bauran pemasaran jasa memiliki pengaruh positif yang signifikan terhadap kepuasan mahasiswa dapat diterima.

Hasil pengujian diperoleh nilai thitung untuk variabel $X 2$ terhadap $Y$ menunjukkan nilai thitung $=5,982$ dengan signifikansi 0,000 . Dengan menggunakan batas signifikansi 0,05 , nilai signifikansi tersebut lebih kecil dari 0,05 dengan arah koefisien positif, sehingga hipotesis yang menyatakan bahwa citra memiliki pengaruh positif yang signifikan terhadap kepuasan mahasiswa dapat diterima.

Nilai koefisien determinasi dapat dilihat pada tabel 8.

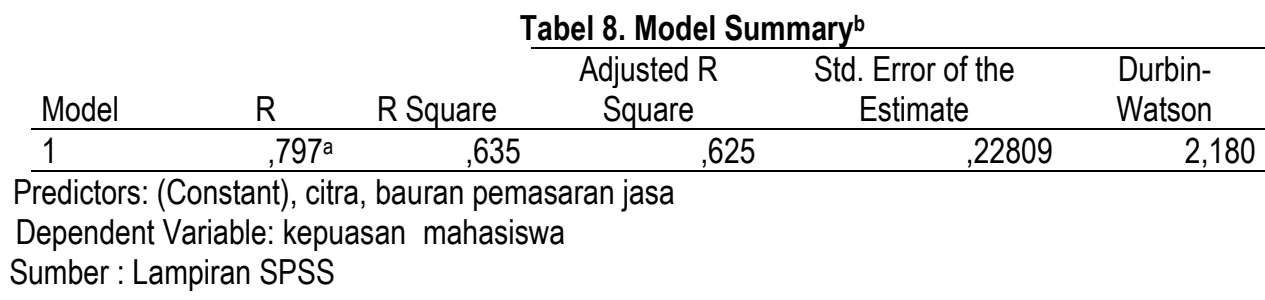

Pada tabel 8 menunjukkan keeratan hubungan antara bauran pemasaran jasa $\left(X_{1}\right)$ dan citra $\left(X_{2}\right)$ dengan kepuasan mahasiswa $(Y)$, dimana nilai $R=0,797$ menunjukkan hubungan yang kuat antara bauran pemasaran jasa $\left(X_{1}\right)$ dan citra $\left(X_{2}\right)$ terhadap kepuasan mahasiswa $(Y)$.

Koefisien determinasi menunjukkan besarnya pengaruh bauran pemasaran jasa $\left(X_{1}\right)$ dan citra $\left(X_{2}\right)$ dengan kepuasan mahasiswa $(Y)$, nilai $R$-Square $=0,635$ menunjukkan besarnya pengaruh bauran pemasaran jasa $\left(X_{1}\right)$ dan citra $\left(X_{2}\right)$ dengan kepuasan mahasiswa (Y) adalah sebesar $63,5 \%$. Dari model ini menunjukkan apabila masih adanya pengaruh dari variabel lain sebesar $36,5 \%$ yang mempengaruhi kepuasan.

Berdasarkan hasil analisis data, pembahasan dari setiap variabel sebagai berikut : (1) Bauran pemasaran jasa secara terpisah mempunyai pengaruh yang signifikan terhadap kepuasan. Sejalan dengan penelitian terdahulu yang dilakukan oleh Muala (2012), membuktikan adanya hubungan signifikan dan positif antara bauran pemasaran dan kepuasan. Soedijati (2011), membuktikan apabila bauran pemasaran berpengaruh pada kepuasan siswa. Sedangkan Cengiz dan Yayla (2007), membuktikan bahwa: bauran 


\section{Efektor, Volume 7 Issue 2, 2020, Pages 98 - 108 \\ Sri Aliami, Ema Nurzainul Hakimah}

pemasaran jasa memiliki pengaruh positif terhadap kepuasan. Peran bauran pemasaran jasa dalam meningkatkan kepuasan mahasiswa, tidak terlepas dari product, price, place, promotion, people, physical evidence, dan process. Zeithaml and Bitner ( 2000:20) menyatakan bahwa, dalam industri jasa marketing mix (4P) telah dimodifikasi dan dikembangkan menjadi 7P yakni : product, price, place, promotion, people, physical evidence, dan process. Dengan demikian, jika bauran pemasaran jasa semakin baik, maka kepuasan akan semakin meningkat. (2) Citra secara parsial memiliki pengaruh yang signifikan terhadap kepuasan mahasiswa. Hal ini mendukung penelitian sebelumnya yang telah membuktikan apabila, citra perguruan tinggi berpengaruh signifikan terhadap kepuasan mahasiswa (Putro: 2016), citra produk berpengaruh terhadap kepuasan pelanggan (Bloemer et al:2002). Andreassen (1994), bahwa citra adalah sebuah faktor penting yang saling berhubungan dengan kepuasan. Farida (2009:183), menyatakan apabila membina dan memperhatikan citra dapat memotivasi pelanggan dan meningkatkan kepuasan pelanggan. Dengan demikian, jika citra perguruan tinggi semakin baik, maka kepuasan akan bertambah. (3) Bauran pemasaran jasa dan citra secara bersama-sama berpengaruh signifikan terhadap kepuasan mahasiswa. Pembuktian tersebut mendukung penelitian Muala (2012), Soedijati (2011), Cengiz dan Yayla (2007), Putro (2016), Bloemer et al (2002), dan Andreassen (1994). Hasil uji antarvariabel pada model summary menunjukkan bauran pemasaran jasa memiliki pengaruh lebih besar daripada citra. Namun demikian, bauran pemasaran jasa dan citra yang dirasakan dibandingkan dengan yang diharapkan, apabila mendekati harapan mahasiswa, maka akan terjadi kepuasan. Bauran pemasaran jasa dan citra yang digambarkan pada kepuasan mahasiswa dapat digunakan sebagai kekuatan perguruan tinggi.

\section{SIMPULAN}

Berdasarkan hasil analisis data dan pembahasan, penelitian ini membuktikan apabila: (1) Bauran pemasaran jasa berpengaruh terhadap kepuasan mahasiswa. (2) Citra berpengaruh terhadap kepuasan mahasiswa. (3) Bauran pemasaran jasa dan citra berpengaruh terhadap kepuasan mahasiswa.

Dari kesimpulan di atas, terdapat beberapa saran untuk: (1) Universitas Nusantara PGRI Kediri sebagai pihak penyelenggara dan pelaksana perguruan tinggi seharusnya selalu berupaya: (a) menciptakan dan mengkreasikan produk jasa yang dapat memberikan nilai manfaat bagi mahasiswa, terutama melalui variasi unit kegiatan mahasiswa (UKM). (b) melengkapi dan meng-update physical evidence terutama sarana prasarana pembelajaran secara terpadu, agar memberikan dukungan pada pencapaian kompetensi lulusan. (c) melakukan sosialisasi dalam rangka untuk menyadarkan pada seluruh civitas akademika terkait dengan makna filosofi dari nama perguruan tinggi. Dengan demikian, identitas perusahaan diharapkan juga memberikan penguatan terhadap pencapaian visi misi. Untuk itu, dalam perumusan visi misi perguruan tinggi seharusnya mampu memberikan inspirasi bagi mahasiswa. Mengingat, citra memiliki pengaruh lebih rendah terhadap kepuasan, maka PTS perlu merumuskan strategi yang tepat untuk membangun citra yang baik berdasarkan pandangan internal maupun eksternal kampus.(2) Penelitian selanjutnya, mengingat penelitian ini hanya mengkaji variabel bauran pemasaran, citra, dan kepuasan, penelitian 


\section{Efektor, Volume 7 Issue 2, 2020, Pages 98 - 108}

Sri Aliami, Ema Nurzainul Hakimah

selanjutnya disarankan untuk menambahkan variabel yang berkaitan dengan kepuasan pelanggan perguruan tinggi seperti yang dikemukakan Levy (Alma, 2016), terutama faktor internal mahasiswa, budaya, prestige, dan perilaku. Selain itu, perlu dikembangkan konsep kepuasan pelanggan sebagai penguat untuk meningkatkan loyalitas pelanggan yang dipengaruhi oleh bauran pemasaran jasa dan citra.

Berorientasi dari saran di atas, peneliti juga mengakui adanya keterbatasan dalam penelitian. Hal tersebut meliputi: (a) Pengambilan sampel penelitian hanya berdasarkan data dari mahasiswa Universitas Nusantara PGRI Kediri, sehingga hasil penelitian ini tidak dapat digunakan sebagai dasar generalisasi. Akan tetapi, dengan penentuan sampel ini dapat memberikan informasi yang lebih spesifik pada Universitas Nusantara PGRI Kediri terutama untuk perusahaan di bidang jasa pendidikan yang memiliki karakteristik heterogen. b) Keterbatasan peneliti mengungkap pengembangan item pernyataan, agar responden mampu mempersepsikan secara lengkap dan komunikatif. (c) Penelitian ini tidak mampu memantau sepenuhnya kesungguhan dan kejujuran responden agar memilih opsi jawaban sesuai dengan keadaan dan kenyataan yang sebenarnya.

\section{DAFTAR RUJUKAN}

Alma, Buchari. 2016. Manajemen Pemasaran dan Pemasaran Jasa. Bandung : Alfabeta.

Andreassen, T. W., 1994. Satisfaction, Loyalty, and Reputation as Indicators of Customer Orientation in the Public Sector. International Journal of Public Sector Management, Vol. 7(2).16-34.

Arikunto, S. 2014. Prosedur Penelitian Suatu Pendekatan Praktik. Jakarta: Rineka Cipta.

Bloomer, J. Andde Ruyter, K. 2002. On The Relationship Between Store Image, Store Satisfaction and Store Loyalty. European Journal of Marketing. Vol. 32 No. 5/6. 499513.

Cengiz, Ekrem danYayla, Hilmi Erdogan. 2007. The Effect of Marketing Mix on Positive Word of Mouth Communication: Evidence from Accounting Offices in Turkey. Journal of Innovative Marketing, Vol. 3, Issue 4. April 11th, 2011. http://www.aabri.com/manuscripts/10627.pdf

Jasfar, Farida. 2009. Manajemen Jasa: Pendekatan Terpadu. Jakarta: GHIm.ia Indonesia.

Kotler, Philip, and Gary Armstrong, 2015. Principles of Marketing. New Jersey: PrenticeInternational.

Muala, Al Ayed and Qurneh Al Majed. 2012. Assessing the Relationship between Marketing Mix and Loyalty through Tourists Satisfaction in Jordan Curative Tourism. Journal American Academic \& Scholarly Research. Vol. 4. No. 2.

Nguyen, Nha dan Leblanc, Gaston. 2001. "Corporate Image and Corporate Reputation in Customer's Retention Decisions in Service" Journal Of Retailing And Consumer Services. Vol. 8, 227-236.

Putro, Baskoro Sri Widodo dan Triastity,Rahayu.2016. Pengaruh Kualitas Pelayanan Jasa dan Citra Perguruan Tinggi terhadap Kepuasan Mahasiswa dengan Word of mouth sebagai Variabel Intervening. Jurnal Ekonomi dan Kewirausahaan Univ. Slamet Riyadi Surakarta. Volume 16. Nomor 3. 
Efektor, Volume 7 Issue 2, 2020, Pages 98 - 108

Sri Aliami, Ema Nurzainul Hakimah

Riduwan. 2017. Dasar-dasar Statistika. Bandung: Alfabeta.

Soedijati, Koes Elizabeth. 2011. Pengaruh Bauran Pemasaran Perguruan Tinggi Terhadap Kepuasan dan Dampaknya Kepada Loyalitas Mahasiswa Pada Tiga PTS

Terkemuka Di Kota Bandung. Jurnal Bina Ekonomi Majalah IImiah Fakultas Ekonomi Unpar. Volume 15. Nomor 2.

Zeithaml, V. A. and Bitner, M. J. 2000. Services Marketing: Integrating Customer Focus Across The Firm. McGraw-Hill.

Idmat. 2011. Keluhan Pelanggan. (http://ft.unmul.ac.id/index.php/id/keluhanpelanggan/keluhan. 11 Juli 2013, 11:24:23 GMT. 